\title{
Application of Premature Chromosome Condensation and Dicentric Analysis in Retrospective Biological Dosimetry of Radiation Accident
}

\author{
A. PaneK ${ }^{a, *}$, J. MiszczyK ${ }^{a}$, C. Paluszkiewicz ${ }^{a}$, E. Pyszka $^{a}$, I. Milcewicz-Mika ${ }^{a}$, \\ S. SMOLiński ${ }^{b, c}$, W. KWIATEK ${ }^{a}$ AND R. Kopé́ ${ }^{a}$ \\ ${ }^{a}$ Institute of Nuclear Physics, Polish Academy of Sciences, PL-31342 Krakow, Poland \\ ${ }^{b}$ Lower Silesian Oncology Center, PL-53413 Wrocław, Poland \\ ${ }^{c}$ University Hospital, PL-50556 Wrocław, Poland
}

\begin{abstract}
Cytogenetic dosimetry based on dicentric analysis and premature chromosome condensation plays an important role in the triage and medical management of affected people in radiological accidents. In our studies, blood samples from persons that were suspected of accidental exposure to ionizing radiation during interventional radiology procedure (plastic surgery of the renal arteries) were investigated for the purpose of the retrospective biological dosimetry of absorbed dose. In this case, the obligatory reported dose value, kerma area product, was high: $106.04 \mathrm{~Gy} \mathrm{~cm}^{2}$. The peak skin dose was reported by X-ray machine system as 17 Gy. Peak skin dose for an iso-centric interventional fluoroscope is measured at defined reference point, located $15 \mathrm{~cm}$ from the isocenter toward the X-ray tube. Due to the lack of possibility to connect kerma area product with an effect (kerma area product could be connected with the maximum local dose in the X-ray field) the patient's blood and 2 most-at-risk people (medical doctors) were investigated. In addition, 5 dosimeters for the whole body $(\operatorname{Hp}(10))$ and 1 ring dosimeter measuring the skin exposure $(\mathrm{Hp}(0.07))$ of medical workers participating in the radiological procedure were investigated. The measurements of individual doses by the thermoluminescent dosimeters were carried out by the Laboratory of Individual and Environmental Dosimetry (Polish acronym LADIS). To estimate the potentially absorbed dose lymphocytes from blood were analyzed for the presence of chromosomal aberrations (dicentrics and rings), which are the "gold standard" assay for biodosimetry. Additionally, the absorbed dose was monitored by the analysis of excess fragments with premature chromosome condensation technique, which is recommended for high doses and partial body exposure. Finally, estimated doses for obtained blood samples were compared to the dose-response curves for dicentrics and premature chromosome condensation excess fragments, detected in our laboratory after induction in human lymphocytes by in vitro X-ray irradiation.
\end{abstract}

DOI: 10.12693/APhysPolA.137.24

PACS/topics: retrospective biological dosimetry, chromosome aberration

\section{Introduction}

At present two main approaches of retrospective dosimetry, biologically-based and physically-based, have been developed. The effective biodosimetric technique must fulfill the following three criteria: the dose can be assessed promptly after-the-fact; the technique can evaluate dose at the level of an individual, and the method should provide information sufficient to determine the type of action that should be taken for that individual [1]. Physically-based dosimetry always incorporates by using a detector that registers results of radiation interaction with matter, for example, the energy of radiation or traces left by radiation.

Biologically-based biodosimetry approaches are based on biological processes or biomarkers that are affected by ionizing radiation. The standard biological dosimetry technique is based on observation of chromosomal aberrations, particularly the presence of dicentric chromosomes in peripheral blood lymphocytes (DCA), which are highly

*corresponding author; e-mail: agnieszka.panek@ifj.edu.pl specific to ionizing radiation and allow for an effective and reliable estimation of the equivalent whole-body dose received $[2,3]$. However, the above method is limited by the necessity to achieve nuclear division resulting in the metaphase which take at least $48 \mathrm{~h}$, therefore not allowing for same-day biodosimetry assessment and it is not applicable for high-dose exposure (>10 Gy) [4].

The limitations of the above method were resolved by the modification of cytogenetic methods by taking advantage of the unique features of cell fusion mediated premature chromosome condensation (PCC) in blood lymphocytes for biological dosimetry [5]. This phenomenon enables visualization, analysis, and quantification of chromosomal aberrations directly in unstimulated G0-peripheral blood lymphocyte prematurely condensed chromosomes (PCCs), without requiring a two-day blood culture $[6,7]$.

The present study aimed to estimate the dose absorbed in lymphocytes of persons that were suspected of accidental exposure to ionizing radiation during interventional radiology (IR) procedure (skin dose 17 Gy) and to compare the potential high-dose radiation exposure indicators on the same specimen to screen the optimal biomarker of high-dose radiation exposure. 


\section{Materials and methods}

Blood samples from 6 persons (patient and 5 medical workers) that were suspected of accidental exposure to ionizing radiation during the same interventional radiology (IR) procedure (plastic surgery of the renal arteries) were collected to heparin tubes. Detailed information on the occupational and medical history of all examined subjects was obtained by completing a targeted questionnaire. Blood samples and 5 dosimeters for the whole body (Hp (10)) and 1 ring dosimeter measuring the skin exposure (Hp (0.07)) of medical workers participating in the radiological procedure were delivered to the Institute of Nuclear Physics, Polish Academy of Sciences after $48 \mathrm{~h}$. Due to the lack of possibility to connect kerma area product (KAP) with an effect the patient's blood and 2 most-at-risk people (medical doctors) were investigated for the purpose of the retrospective biological dosimetry of absorbed dose.

\section{Physical dosimetry}

The measurements of individual doses, in terms of individual dose equivalent for whole body $\mathrm{Hp}(10)$ and individual dose equivalent for skin $\mathrm{Hp}(0.07)$ of medical staff taking part in the radiological procedure were carried out by the Laboratory of Individual and Environmental Dosimetry (LADIS) [8]. The laboratory runs a dosimetry service based on thermoluminescent dosimeters and is accredited according to PN-EN ISO 17025:2005 standard [9] by the Polish Center for Accreditation. Measurements of doses for people working with ionizing radiation are obligatory in Poland according to Polish law [10]. For both whole body and ring dosimeters used in the measurements lithium fluoride detectors doped with magnesium and titanium $\mathrm{LiF}: \mathrm{Mg}, \mathrm{Ti}$ were applied. Dosimeters sent back to the laboratory after the measurement period underwent the standard procedure of readout. Dosimeters were first annealed at temperature of $75^{\circ} \mathrm{C}$ for 30 and $10 \mathrm{~min}$ for whole body and ring dosimeters, respectively, and cooled down on a thick aluminum plate. After cooling down automatic readout in RADOS RE-2000 reader in $340^{\circ} \mathrm{C}$ was performed. The measurement range is $0.1 \mathrm{mSv}-10 \mathrm{~Sv}$ for $\mathrm{Hp}(10)$ and $0.1 \mathrm{mSv}-1 \mathrm{~Sv}$ for $\mathrm{Hp}(0.07)$.

\section{Biological dosimetry}

\subsection{Culturing, slide preparation}

Cultures were set up according to standard procedures $[11,12]$. Briefly, whole blood $(0.5 \mathrm{ml})$ was added per $4.5 \mathrm{ml}$ of the RPMI 1640 culture medium (PAA Laboratories GmbH Pasching, Austria) that was supplemented with 20\% fetal calf serum (Gibco, Carlsbad, United States), antibiotics, and a small amount of bromodeoxyuridine. Lymphocytes were stimulated with PHA (10 mg/ml) (Sigma-Aldrich, St. Louis,
United States). The cultures were incubated for $48 \mathrm{~h}$ at $37^{\circ} \mathrm{C}, 5 \% \mathrm{CO}_{2}$. Two hours before the end of culturing, $0.1 \mu \mathrm{l} / \mathrm{ml}$ of colcemid solution was added to each DCA culture. In the case of PCC culture, in exact $30 \mathrm{~min}$ before ending the culturing process calyculin A (50 nM) was added to the culture medium. Then, the cells were fixed as well as stained with Giemsa for PCC and a fluorescence plus Giemsa solution ((Merck Millipore, Darmstadt, Germany) for chromosome preparations following a standard procedure described elsewhere [11].

\subsection{Chromosome aberration analysis and dose estimation}

Chromosome analysis was performed according to the International Atomic Energy Agency (IAEA) manually $[2,13]$ by a trained, experienced observer. Cells finding and image capturing were performed on a Nicon E-200 microscope. The frequency of dicentrics per cell in 46 chromosomes was scored manually in an openaccess graphic program ImageJ.

A conventional dose-effect curve obtained from in vitro irradiation experiments using X-rays $(250 \mathrm{kV}, 10 \mathrm{~mA})$ was used to estimate the exposure dose of victims. The calibration curve was generated by fitting the yield of aberrations to linear-quadratic dose dependencies. The dose estimations and the corresponding 95\% confidence intervals according to the number of dicentrics plus centric rings were performed with the free software CABAS V2.0 [14]. Curve fitting was done by least square regression method and the quality of the fit was tested by the chi-squared test. The dose-effect relationship was $Y=0.0015( \pm 0.0017)+0.047( \pm 0.0124) \times D+$ $0.054( \pm 0.007) \times D^{2}$, where $Y$ equals the number of dicentrics plus centric rings per cell and $D$ equals the dose in Gy. The dose range used for the calibration curve was from 0.3 to $4 \mathrm{~Gy}$.

\subsection{PCC excess fragments analysis and dose estimation}

Cells finding and image capturing were performed on a Metafer 4 scanning system (MetaSystems, Germany) equipped with a Zeiss Axio Imager Z2 microscope. The PCC fragments per cell in excess of 46 PCC chromosomes were scored manually for each experimental point in aprogram ImageJ. For PCC test the data analysis was performed using the Microsoft Office Excel 2013 program and the sum of the PCC excess fragments was obtained by the OriginPro 9.064 bit (OriginLab, Northampton, $\mathrm{MA})$. The error given in each measurement point is the standard deviation (SD) of the mean [11].

A PCC excess fragments dose-effect curve obtained from in vitro irradiation experiments using high doses of X-rays $(250 \mathrm{kV}, 10 \mathrm{~mA})$ was used to estimate the exposure doses of the victim. The dose-effect relationship was $Y=4.64( \pm 1.63)+25.14( \pm 2.41) \times D+0.70( \pm 0.21) \times D^{2}$, where $Y$ equals the sum of PCC excess fragments in analyzed cells (50 cells) and $D$ represents the dose in Gy; the used dose range was from 1 to $20 \mathrm{~Gy}$. 


\section{Results and discussion}

As a result of measurements, 5 values of $\mathrm{Hp}(10)$ and one value of $\mathrm{Hp}(0.07)$ were provided. Results of measurements are presented in Table I showing no increase in dose received by medical staff during the procedure. Only based on the ring dosimeter the individual dose equivalent of $2.11 \pm 0.12 \mathrm{mSv}$ was detected. The results of measurements thus cannot yield any information on the exposure and risks to the donor.

The retrospective biological dosimetry was performed for three persons that were suspected of accidental exposure to ionizing radiation during interventional radiology (IR) procedure. Chromosomal aberration (DCA) and PCC tests were used for estimation of absorbed dose of ionizing radiation [15]. Table II presents the number of unstable CA (dicentrics and rings) in lymphocytes as well as their frequencies per cell for three potentially exposed persons. Obtained results showed the dicentrics presence only for a patient sample coded as CA-1-03-2015 (0.012 dic/cell) and a one medical worker CA-3-03-20153 (0.017 dic/cell). For secondary worker sample CA-2-03-2015 dicentrics were not observed. To identify partial body exposure the distribution of dicentrics was analyzed as a deviation from Poisson with the u-test [16]. In case the u-test was significant, a partial body dose was estimated together with the irradiated volume of the body using the Dolphin method [13]. The test for the Poisson distribution (Table II) showed that the distribution of dicentrics plus centric rings in peripheral blood lymphocytes of both victims followed a Poisson distribution $(u<| \pm 1.96|)$. The absorbed dose of ionizing radiation was estimated with using by our $\mathrm{X}$-ray induced dose-dependent calibration curve based on dicentric chromosomes plus centric rings (Fig. 1a) and amounted to 0.21 Gy for patient and 0.29 Gy for medical worker (CA-3-03-2015). The estimated doses may suggest low exposure of the donor and medical personnel, which might be due to the morphological picture of the analyzed cells showing poor cell division and a low number of good quality metaphases. This problem confirms many researchers [17-19], which pointed out that problems with complete nuclear division influencing reliable biodosimetry for high-dose exposure (>10 Gy), because an insufficient amount of dividing cells can be obtained.

TABLE I

Measurement results of thermoluminescent dosimeters.

\begin{tabular}{c|c|c}
\hline \hline $\begin{array}{c}\text { Medical } \\
\text { worker no. }\end{array}$ & $\begin{array}{c}\text { Whole body } \\
\text { dose equivalent } \\
\operatorname{Hp}(10)[\mathrm{mSv}]\end{array}$ & $\begin{array}{c}\text { Individual } \\
\text { dose equivalent } \\
\text { for skin } \operatorname{Hp}(0.07)[\mathrm{mSv}]\end{array}$ \\
\hline 1 & $<0.1$ & - \\
2 & $<0.1$ & - \\
3 & $<0.1$ & - \\
4 & $<0.1$ & - \\
5 & $<0.1$ & $2.11 \pm 0.12$
\end{tabular}
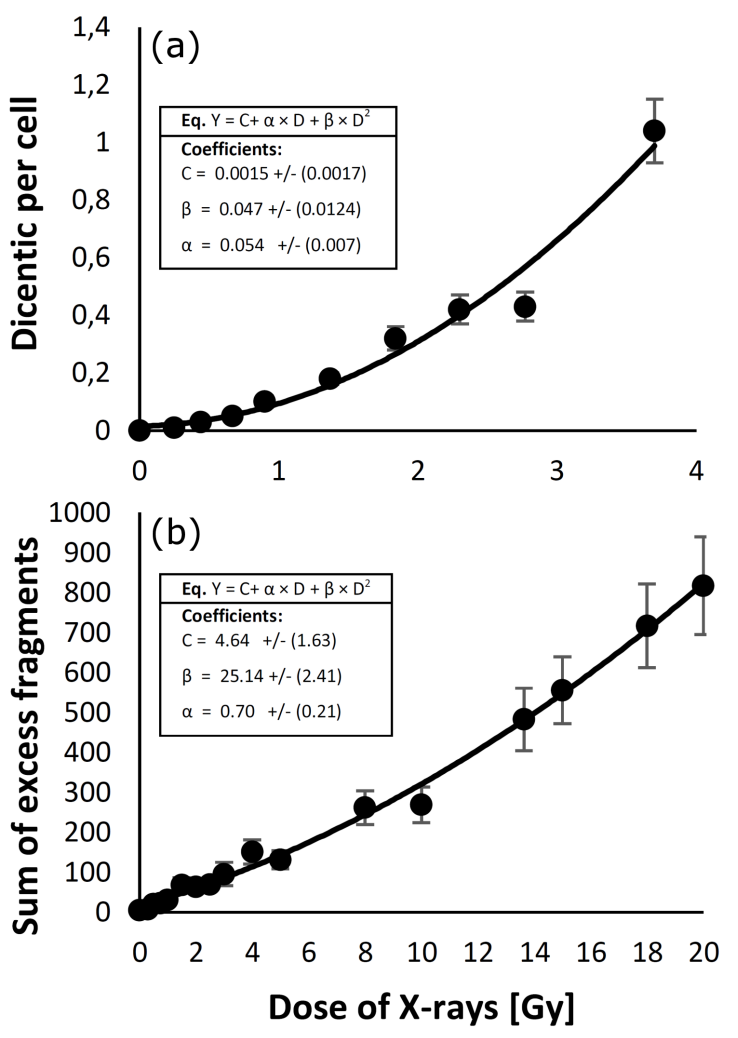

Fig. 1. The whole-body of X-rays induced dosedependent calibration curves based on dicentric chromosomes plus centric rings (a) and the sum of PCC excess fragments in analyzed cells (b).

In comparison with conventional cytogenetic technique, the potential advantage of PCC assay is to eliminate the problem of mitotic delay and interphase death leading to an underestimation of the dose $[19,20]$. In our studies, for patient after the accident the PCC excess fragments analysis was performed in 50 cells in G2/M phase. Results of the sum of PCC excess fragments in lymphocytes as well as their frequencies per cell are presented in Table III. As might be seen from PCC excess chromosome fragments $(1.2 /$ cell $)$ are overdispersed for a studied person, showing $u$ value $>1.96$. From the whole-body of X-ray induced dose-dependent calibration curve based on the sum of PCC excess fragments in analyzed cells (Fig. 1b) estimated absorbed dose of ionizing radiation was matched as $2.08 \mathrm{~Gy}$. The obtained results confirmed the high probability of occurring of accidental situation, however, with a large underestimation of the potential absorbed dose. On the other hand, the obtained information regarding the exposure conditions as well as the distribution of chromosomal defects suggest partial body exposure. Therefore, an attempt was made to estimate the partial body dose using the $\mathrm{Q}_{\mathrm{PCC}}$ method [19, 21, 22]. Obtained results (Table III) showed that the partial-body dose evaluated on the base of PCC excess fragments in damaged cells calibration curve was $13.15 \pm 2.53 \mathrm{~Gy}$. 
TABLE II

Comparison of the results of frequency and distribution of dicentrics and estimation of absorbed dose in samples of human peripheral blood taken from three persons accidentally exposed.

\begin{tabular}{|c|c|c|c|c|c|c|c|c|c|c|}
\hline & \multirow{2}{*}{$\begin{array}{c}\text { Cells } \\
\text { scored }\end{array}$} & \multirow{2}{*}{ Dic } & \multirow{2}{*}{$\begin{array}{c}\text { Dic } \\
\text { per cell }\end{array}$} & \multicolumn{2}{|c|}{ Aberrations } & \multirow{2}{*}{$\begin{array}{l}\sigma^{2} / y \\
\text { ratio }\end{array}$} & \multirow{2}{*}{$\mu$} & \multirow{2}{*}{$\begin{array}{r}\text { Estimated } \\
\text { dose [Gy] }\end{array}$} & \multicolumn{2}{|c|}{ Dose } \\
\hline & & & & $95 \%$ LCL & $95 \%$ UCL & & & & $95 \%$ LCL & $95 \%$ UCL \\
\hline $\begin{array}{l}\text { patient } \\
\text { CA-1-03-2015 }\end{array}$ & 259 & 3 & 0.012 & 0.62 & 8.77 & 0.99 & -0.11 & 0.21 & 0.03 & 0.52 \\
\hline $\begin{array}{l}\text { medical worker } \\
\text { CA-2-03-2015 }\end{array}$ & 251 & 0 & 0.0 & 0 & 0 & & & - & - & - \\
\hline $\begin{array}{l}\text { medical worker } \\
\text { CA-3-03-2015 }\end{array}$ & 116 & 2 & 0.017 & 0.24 & 7.22 & 0.99 & -0.09 & 0.29 & 0.02 & 0.80 \\
\hline
\end{tabular}

In all samples the distribution of dicentrics in cells followed the Poisson distribution

TABLE III

Results of PCC excess fragments analysis and estimation of absorbed dose in human peripheral blood from person accidentally exposed.

\begin{tabular}{|c|c|c|c|c|c|c|c|c|}
\hline \multicolumn{9}{|c|}{ Whole body dose estimation } \\
\hline Patient & $\begin{array}{c}\text { Cells } \\
\text { scored } \\
\end{array}$ & $\begin{array}{c}\text { PCC excess } \\
\text { fragm. }\end{array}$ & $\pm \mathrm{SD}$ & $\begin{array}{l}\text { PCC excess } \\
\text { fragm./ cell }\end{array}$ & $\sigma^{2} / y$ ratio & $\mu$ & $\begin{array}{c}\text { Estimated } \\
\text { dose [Gy] }\end{array}$ & $\pm \mathrm{SD}$ \\
\hline PCC-1-03-2015 & 50 & 60.00 & \pm 30.89 & 1.2 & 14.7 & 68.3 & 2.08 & \pm 2.53 \\
\hline \multicolumn{9}{|c|}{ Partial body dose estimation ( $Q_{\mathrm{PCC}}$ method) } \\
\hline Patient & $\begin{array}{c}\text { Cells } \\
\text { damaged }\end{array}$ & & & $\begin{array}{l}\text { PCC fragm. } \\
\text { / dam. cell }\end{array}$ & $95 \%$ LCL & $95 \%$ UCL & $\begin{array}{c}\text { Estimated } \\
\text { dose [Gy] }\end{array}$ & $\pm \mathrm{SD}$ \\
\hline PCC-1-03-2015 & 8 & & & 7.5 & 45.8 & 77.2 & 13.15 & \pm 3.19 \\
\hline
\end{tabular}

and overdispersion parameter $(\mu)$. A $\mu$ value $>1.96$ indicates that the distribution is significantly overdispersed.

\section{Conclusion}

The conventional dicentric assay with low background and high specificity may be a good indicator for biological dose evaluation. However, it has limitations while estimating high dose exposure. Therefore, apart from the dicentric assay, it seems appropriate to use other methods available, such as the PCC assay. Considering the time needed to give a dose estimate from a blood sample and lack of cell divide problems, the PCC technique appears quicker and more flexible than conventional cytogenetics and could be applied as an additional screening method to an accidental situation.

\section{Acknowledgments}

The research was performed by using the equipment purchased within the project co-funded by the Małopolska Regional Operational Program Measure 5.1 Krakow Metropolitan Area as an important hub of the European Research Area for 2007-2013 (No. MRPO.05.01.00-12-013/15). The PCC method was introduced and elaborated for biodosimetry purposes at IFJ PAN via the grant DEC-2013/09/D/NZ7/00324 financed by the National Science Centre, Poland.

\section{References}

[1] H.M. Swartz, A.B. Flood, R.M. Gougelet, M.E. Rea, R.J. Nicolalde, B.B. Williams, Health Phys. 98, 95 (2010).

[2] International Atomic Energy Agency, Technical Report Series No. 405, IAEA, Vienna 2001.

[3] L. Roy, E. Gregoire, V. Durand, V. Buard, M. Delbos, N. Paillole, I. Sorokine-Durm, P. Gourmelon, P. Voisinet, Int. J. Radiat. Biol. 82, 39 (2006).

[4] M. Fenech, Radiat. Meas. 46, 737 (2011).

[5] R. M'Kacher, E. El Maalouf, G. Terzoudi, M. Ricoul, L. Heidingsfelder, I. Karachristou, et al., Int. J. Radiat. Oncol. Biol. Phys. 91, 640 (2015).

[6] I. Karachristou, M. Karakosta, A. Pantelias, V.I. Hatzi, P. Karaiskos, P. Dimitriou, G. Pantelias, G.I. Terzoudi, Mutat. Res. 793, 107 (2015).

[7] A.I. Lamadrid Boada, I. Romero Aguilera, G.I. Terzoudi, J.E. Gonzalez Mesa, G. Pantelias, O. Garcia, Mutat. Res. 757, 45 (2013).

[8] M. Budzanowski, R. Kopeć, B. Obryk, P. Olko Radiat. Protect. Dosim. 144, 107 (2011).

[9] PN-EN ISO/IEC 17025:2005 standard — "General requirements for the competence of testing and calibration laboratories".

[10] Atomic Law 2000. The Act of November 29, 2000 (consolidated text Journal of Laws of 2018, item 792). 
[11] K. Rawojć, J. Miszczyk, A. Możdżeń, J. Swakoń, A. Sowa-Staszczak, Int. J. Radiat. Biol. 94, 996 (2018).

[12] A. Galas, J. Miszczyk, PLOS ONE 11, (2016).

[13] International Atomic Energy Agency, EPRDosimetry 2011, IAEA, Vienna 2011.

[14] J. Deperas, M. Szluinska, M. Deperas-Kaminska, A. Edwards, D. Lloyd, C. Lindholm, H. Romm, L. Roy, R. Moss, J. Morand, A. Wojcik, Radiat. Protect. Dosim. 124, 115 (2007)

[15] U. Oestreicher, D. Samaga, E. Ainsbury, A.C. Antunes, A. Baeyens, L. Barrios et al., Int. J. Radiat. Biol. 93, 20 (2017).

[16] G.D. Papworth, Curr. Top Radiat. Res. 6, 129 (1970).
[17] C. Lindholm, D. Stricklin, A. Jaworska, A. Koivistoinen, W. Paile, E. Arvidsson, J. Deperas-Standylo, A. Wojcik, Radiat. Res. 173, 71 (2010).

[18] B. Rungsimaphorn, B. Rerkamnuaychoke, W. Sudprasert, Genome Integr. 7, 8 (2016).

[19] G.I. Terzoudi, G. Pantelias, F. Darroudi, K. Barszczewska, I. Buraczewska, J. Depuydt, Int. J. Radiat. Biol. 93, 48 (2017).

[20] B. Yao, Y. Li, G. Liu, M. Guo, J. Bai, Q. Man, L. Qiu, H. Ai, Mutat. Res. 751, 66 (2013).

[21] W.F. Blakely, G.P. Prasanna, C.J. Kolanko, M.D. Pyle, D.M. Mosbrook, A.S. Loats, T.L. Rippeon, H. Loats, Stem Cells 13, 223 (1995).

[22] X. Lu, H. Zhao, J.B. Feng, X.T. Zhao, D.Q. Chen, Q.J. Liu, Mutat. Res. 807, 47 (2016). 